\title{
Idiopathic Adult Onset Fanconi's Syndrome in a Patient Treated with Oxaliplatin
}

\author{
Nguyen A and Benz S* \\ Department of Medicine, Medical College of Wisconsin, \\ USA \\ *Corresponding author: Samantha Benz, Department \\ of Medicine, Medical College of Wisconsin, Wauwatosa, \\ Wisconsin, USA
}

Received: April 09, 2021; Accepted: April 26, 2021; Published: May 03, 2021

\begin{abstract}
Proximal tubular injury is known complication of chemotherapy such as carboplatin. However, there are far more other causes of injury and in many situations, the etiology is difficult to elucidate. Here we describe a case of a patient who presented with a urine analysis consistent of Fanconi's syndrome with signs and symptoms of the disorder prior to chemotherapy but requiring admission for aggressive electrolyte replacement soon after the chemotherapy was completed. We further discuss causes of Fanconi's syndrome and the importance of evaluation of the proximal convoluted tubule prior to administration of chemotherapy.
\end{abstract}

Keywords: FOLFOX; Fanconi's syndrome

\section{Introduction}

Fanconi's syndrome is a rare disease that is characterized by wasting of glucose and electrolytes that are typically reabsorbed by the proximal convoluted tubule of the nephron. Since this portion of the nephron is so active in reabsorption of electrolytes, it is also prone to damage when it's metabolic demands are not met. Here we describe a case of a man with a likely preexisting Fanconi's syndrome who developed profound glucose and electrolyte wasting after receiving FOLFOX which is typically not associated with development of Fanconi's syndrome.

\section{Case}

Pt is a 78-year-old male with a past medical history of stage IV colon cancer. Patient presented with a chief compliant of near syncope. Pt has found to have a urinalysis significant for $>1000 \mathrm{mg} /$ $\mathrm{dl}$ of glucose, and $100 \mathrm{mg} / \mathrm{dl}$ of protein. Blood studies were significant for hypoalbuminea at $1.7 \mathrm{~g} / \mathrm{dL}$, and normal electrolytes with a potassium of $3.5 \mathrm{mmol} / \mathrm{L}$, sodium of $132 \mathrm{mmol} / \mathrm{L}$, magnesium of 2.3 $\mathrm{mg} / \mathrm{dL}$, and phosphorus of $1.3 \mathrm{mg} / \mathrm{dL}$. Urine electrolytes were notable for an elevated potassium of $69.2 \mathrm{mmol} / \mathrm{L}$ and sodium of $52 \mathrm{mmol} / \mathrm{L}$. Microalbumin was elevated at $22.0 \mathrm{mg} / \mathrm{dL}$. The total protein was 2549 $\mathrm{mg} / 24 \mathrm{H}$. Fractionated proteins in the urine resulted with albumin $17.90 \mathrm{mg} / \mathrm{dL}$, Alpha-1 globulin $16.30 \mathrm{mg} / \mathrm{dL}$, alpha-2 globulin 20.82 $\mathrm{mg} / \mathrm{dL}$, beta globulin $24.68 \mathrm{mg} / \mathrm{dL}$, gamma globulin $14.51 \mathrm{mg} / \mathrm{dL}$, the total random urine protein was elevated at $2035 \mathrm{mg} / 24 \mathrm{hour}$. Free kappa light chain was elevated at $25.00 \mathrm{mg} / \mathrm{dL}$, free lambda light chain was $16.97 \mathrm{mg} / \mathrm{L}$, with a Kappa/Lambda ratio of 1.47. Patient's glucose was 500 on a urine analysis four years prior.

Pt was negative for lead and had no history which caused us to suspect venom or other rarer causes of Fanconi's syndrome. Patient completed one cycle of FOLFOX approximately one week prior to hospitalization with oxaliplatin. History was evaluated extensively for causes of Fanconi's syndrome and was negative for lead poisoning, animal bites, or topic medications.

\section{Treatment}

Electrolytes were aggressively replaced.

\section{Outcome and Follow up}

Repeat urine studies continued to show increased glucose in the urine. Patient did not recover function of his proximal convoluted tubule. Urine analysis continued to show glucose in the urine.

\section{Discussion}

Adult-acquired Fanconi syndrome is a rare condition generalized by wasting of amino acids, glucose, phosphate, uric acid and various ions from the proximal renal tubule. The diagnosis of Fanconi syndrome could be made by the following findings of aminoaciduria, hypophosphatemia and findings of renal tubular acidosis (type 2) [1]. The pathophysiology of Fanconi syndrome lies in the defect in the proximal convoluted tubule whereby the reabsorption capacity of the kidney becomes reduced. As a result, abnormalities such as amino acid, glucose, phosphate, and bicarbonate are found in the urine within this patient group.

While most cases of adult onset Fanconi's syndrome is typically associated with monoclonal gammopathy, in our case there was no evidence of monoclonal gammopathy [2]. It is unlikely that in our case the oxaliplatin given to the patient caused the proximal tubular damage on top of a developing Fanconi's syndrome, as the glucose in the patient's urine was elevated prior to the first cycle of FOLFOX. Further, our patient still has evidence of Fanconi's syndrome a month after treatment. It is increasingly important for evaluation and planning in regard to the number of checks needed for a patient in post chemo follow-up.

Other causes of Fanconi syndrome features disruptions to mitochondrial functioning as the primary mechanism. In a paper by Klootwijk et al. an EHHADH gene was identified that encodes for a peroxisomal enzyme [3]. When this encoded enzyme is mutated, it mistargets mitochondria, instead of peroxisomes, leading to disruption of fatty acid oxidation and an energy production. This disruption causes mitochondrial damage and leakage of metabolites consistent with a phenotype of Fanconi Syndrome. Another common cause of Fanconi syndrome is by drug induction. The most common culprits of drug-induced Fanconi Syndrome includes valproic acid, 
aminoglycosides, and cisplatin. Numerous of studies have found a link between these medications with mitochondrial toxicity and the manifestation of the Fanconi phenotype [4]. Overall, while the exact underlying mechanism for Fanconi Syndrome has not been elucidated, the mitochondria play an integral role in generating the ATP necessary for active transport in the proximal convoluted tubule. Disruption to these essential organelles have been shown in both the drug-induced and hereditary models to lead to a biochemical presentation consistent with Fanconi Syndrome [4]. The astute clinician should be well aware of the possibility of a co-occurring idiopathic Fanconi's Syndrome and the necessity of close monitoring to prevent fatal arrythmias.

\section{Learning Points}

- Underlying Fanconi's syndrome should be evaluated prior to patient's receiving chemotherapy.

- It is possible that chemotherapy which is not know to cause Fanconi's may push a pre-damaged kidney into a Fanconi's syndrome. Clinicians should be diligent in this evaluation.

\section{References}

1. Karatzas A, Paridi D, Kozyrakis D, Tzortzis V, Samarinas, M, Dailiana Z, et al. Fanconi syndrome in the adulthood. The role of early diagnosis and treatment. Journal of musculoskeletal \& neuronal interactions. 2017; 17303 306.

2. Messiaen T, Deret S, Mougenot B, Bridoux F, Dequiedt $P$, et al. Adult Faconi Syndrome secondary to light Chain Gammopathy: Clinicopathologic heterogeneity and unnsual features in 11 patients. Medicine. 2000; 79: 135154

3. Klootwijk ED, Reichold M, Helip-Wooley A, Tolaymat A, Broeker C, Robinette $\mathrm{SL}$, et al. Mistargeting of Peroxisomal ehhadh and Inherited renal Fanconi's Syndrome. New England Journal of Medicine. 2014; 370: 129-138.

4. Heidari R, Jafari F, Khodaei F, Yeganeh BS, Niknahad H. Mechanism of valproic acid-induced Fanconi syndrome INVOLVES mitochondrial dysfunction and oxidative stress in rat kidney. Nephrology. 2018; 23: $351-$ 361. 